\title{
Clinical features and survival of patients with hepatocellular carcinoma at a cancer treatment facility
}

\author{
Hala Mansoor ${ }^{*}$, Muhammad Adnan Masood, Kashif Siddique, Farhana Badar, Muhammed Aasim Yusuf
}

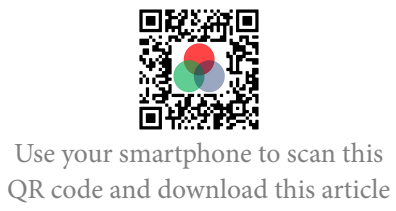

Shaukat Khanum Memorial Cancer Hospital \& Research Centre Lahore, Pakistan

Correspondence

Hala Mansoor, Shaukat Khanum Memorial Cancer Hospital \& Research Centre Lahore, Pakistan

Email: hmansoorahmad@gmail.com

History

- Received: Oct 24, 2019

- Accepted: Nov 11, 2019

- Published: Nov 29, 2019

DOI : $10.15419 /$ bmrat.v6i11.577

\section{Check for updates}

\section{Copyright}

( ) Biomedpress. This is an openaccess article distributed under the terms of the Creative Commons Attribution 4.0 International license.

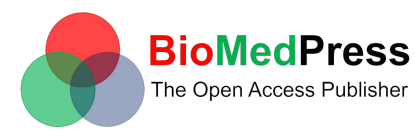

\begin{abstract}
Background: Hepatocellular carcinoma (HCC) is the third leading cause of cancer-related deaths. This study aimed to determine the survival of patients with HCC at our treatment facility. Methods: We retrospectively studied 278 patients with HCC who were seen between 2007 and 2013. Of these patients, $84.4 \%$ had evidence of prior infection with hepatitis C, while $7.8 \%$ had markers of hepatitis B infection. Results: Median survival was 24.6 months for transarterial chemoembolization (TACE), 61 months for ablative therapies, and 31.5 months for those undergoing surgical resection. Increasing tumor size, multifocality, advanced Barcelona clinic liver cancer (BCLC) stage, and poor liver function (Child-Pugh class B-C) were significantly associated with worse prognosis; $\mathrm{p}$ values were $0.002,0.009,<0.001$, and $<0.001$, respectively. Conclusion: Most patients in our series presented with advanced liver disease, with multifocal tumors and were candidates for palliative treatment only. Public education to minimize hepatitis B and C transmission, screening programs to detect disease at an earlier stage, and the development of specialist liver units and liver transplant programs can bring a change in HCC survival in developing countries.

Key words: Hepatocellular carcinoma, survival, Pakistan
\end{abstract}

\section{INTRODUCTION}

Hepatocellular carcinoma (HCC) is common, and although it affects different regions of the world disproportionately, worldwide it remains the seventh most frequent cancer and the third most common cause of cancer-related deaths, causing approximately 600,000 deaths annually ${ }^{1-3}$. Its incidence has almost doubled in Western countries in the past 20 years, primarily due to an increase in alcohol and hepatitis C-related liver cirrhosis ${ }^{4,5}$. However, more than $80 \%$ of cases occur in the developing world and in areas with a high prevalence of hepatitis B and C, such as China, southeast Asia, and Sub-Saharan Africa, where its incidence is as high as $>20 / 100,000^{1,3,6}$. With universal screening of high risk populations, early detection and treatment, the five-year survival rate of those with HCC can be as high as $70 \%$, after ablation, resection or liver transplant. Patients in whom HCC is detected by surveillance have a three-year survival rate of $50.8 \%$, compared to $28.2 \%$ in those not on a surveillance program. This difference in survival is largely due to detection at an earlier stage, with better resultant treatment options ${ }^{7}$.

In intermediate stage HCC, the two-year survival rate is $49 \%$, while median survival is 16 months; in advanced stage HCC, the one-year survival is $11 \%$ with a median survival of 3-4 months ${ }^{8,9}$.

\section{METHODS}

\section{Evaluations}

We retrospectively analyzed demographic, etiological, clinical and therapeutic variables of 278 patients with HCC, treated at the tertiary care Shaukat Khanum Memorial Cancer Hospital and Research Center, in Lahore, Pakistan from May 2007 til December 2013. They were treated after obtaining exemption for approval from the Institutional Review Board. The study was retrospective, in accordance with the principles of Helsinski's declaration. Data was collected using the computerized hospital database, and from evaluating the clinical and multidisciplinary team meeting notes, pathology and radiology reports, and information obtained from patients and their families by telephonic surveys.

The purpose of this study was to evaluate the survival of patients with HCC arising as a result of a variety of etiologies and to attempt to correlate survival with liver function, tumor focality, size, and stage, as well as with serum alpha-fetoprotein level and treatment regimen.

In the majority of our patients, the initial liver lesion was detected on ultrasonography, and then further evaluated by multiphase computed tomography (CT) scan. The diagnosis was based, for the most part, on 
characteristic findings on imaging, in appropriatelysized lesions in a typical clinical setting, following EASL/AASLD guidelines. Lesions that showed multiphase magnetic resonance imaging (MRI) were further evaluated for atypical vascular enhancement pattern on multiphase CT scan. If on MRI the tumor showed characteristic radiological features of HCC, then the diagnosis of HCC was considered to be confirmed, assuming again an appropriate clinical setting. If the lesion remained atypical on MRI, imageguided liver biopsy was performed, and the diagnosis was established if it showed the characteristic histological features of HCC.

The demographic and clinical characteristics of the study population are shown in Table 1. Hepatitis C virus infection, detected either by HCV antibodies by third generation ELISA or by HCV RNA by polymerase chain reaction (PCR), was the most common risk factor for chronic liver disease. HCV infection was present, either alone or in combination with diabetes mellitus, in $83 \%(231 / 278)$ of the study population. Hepatitis B virus infection (detected by the presence of hepatitis B surface antigen or by HBV DNA by PCR), either alone or in combination with diabetes mellitus, was the second most common risk factor, and was present in $7.8 \%(22 / 278)$ of the patients; five of these patients also had hepatitis C. Alcohol consumption, as the only risk factor, was present in only two patients, but was present in another eight patients in combination with diabetes and accounted for 3.6\% $(10 / 278)$ of the study population.

The number of patients with unifocal (50.4\%; 140/278) and multifocal (49.6\%; 138/278) tumors were very similar. However, only $16.2 \%$ of patients had tumors $<3 \mathrm{~cm}$ in size, while $83.8 \%$ had tumors $\geq 5$ $\mathrm{cm}$. Multiphasic CT scan was the means of diagnosis in $82.7 \%(230 / 278)$ of patients, multiphasic MRI in $6.5 \%$ (18/278), and liver biopsy in $10.8 \%$ (30/278). All patients were discussed, and treatment decisions were made in multidisciplinary team meetings, which were attended by gastroenterologists/hepatologists, pathologists, surgeons with interest in liver surgery, radiologists and medical oncologists. During the period of the study, no liver transplant program existed in Pakistan, and so those who could afford to travel overseas for this procedure did so. Recently, a liver transplant facility has been established in the private sector. All other patients, including those for whom liver transplant was recommended but was not possible for financial reasons, were treated at our institution.

\section{Statistical analysis}

Cumulative survival analysis was calculated using the Kaplan-Meier method. The duration of survival was calculated from the time of HCC diagnosis until the death of the patient or last follow-up visit. Log Rank (Mantel Cox) test was used to evaluate the equality of survival distribution for different levels of variables under consideration. A $p$-value less than 0.05 was considered to be statistically significant. The Statistical Package for Social Sciences (SPSS) software, version 19 , was used to conduct the analysis.

\section{RESULTS}

There were $192 / 278$ males in the study, accounting for $69 \%$ of the study population. The mean age of the 278 cases was $60.1 \pm 9.2$ years (range 16-87 years, median $59.5 \mathrm{y}$ ). One hundred and eighty-one patients $(65.1 \%)$ underwent trans-arterial chemo-embolization (TACE). Twenty-three (8.3\%) were treated by a combination of TACE plus another modality. These included resection, radiofrequency ablation (RFA), percutaneous ethanol injection (PEI), or the tyrosine kinase inhibitor, sorafenib. Twelve patients $(4.3 \%)$ underwent ablation procedures (RFA/PEI), while $6(2.2 \%)$ underwent surgical resection. Fourteen patients $(5 \%)$ received sorafenib alone, while 42 (15.1\%) were deemed suitable for supportive care only.

Overall survival for the entire cohort was 23.9 months. The median survival of patients who had an ablative procedure was 61 months, while in those who had TACE in combination with another treatment modality, it was 44 months. Median survival was 31.5 months for those undergoing surgical resection, 24.6 months in those who underwent TACE, 9.6 months in those treated with sorafenib, and 3.6 months for those on supportive care. There were significant differences in survival when patients who underwent TACE alone were compared with those who had either TACE in combination with other treatments (such as resection, RFA, PEI or sorafenib) or an ablative procedure (such as RFA or PEI) (Chi-sq.=3.90, p=0.048). However, when other treatments were compared with TACE, the difference in survival was not significant; Figure 1 shows survival from TACE versus surgical resection or sorafenib. Patients with unifocal tumors $(140,50.4 \%)$ had a significantly better median overall survival of 26.7 months, compared to 17.4 months for those with multifocal tumors (138 patients, $49.6 \%$ ) (Figure 2). Overall, there was a significant difference in survival by tumor size (Chi-sq. $=12.61, \mathrm{df}=2$, $\mathrm{p}=0.002$ ). Sub-group analysis showed a significant 
Table 1: Demographics and clinical profile of the patients

\begin{tabular}{|c|c|c|}
\hline Variables & $\mathrm{n}$ & $\%$ \\
\hline Mean age (SD) & $60(9.2)$ & \\
\hline \multicolumn{3}{|l|}{ Gender } \\
\hline Male/female & $192 / 86$ & $69 / 31$ \\
\hline \multicolumn{3}{|l|}{ Cirrhosis } \\
\hline Child-Pugh Class A & 234 & 84 \\
\hline Child-Pugh Class B & 32 & 11.5 \\
\hline Child-Pugh Class C & 12 & 4.3 \\
\hline \multicolumn{3}{|l|}{ Risk factors } \\
\hline Hepatitis C & 150 & 54 \\
\hline Hepatitis C+DM & 81 & 29 \\
\hline Hepatitis $\mathrm{B} \pm \mathrm{DM}$ & 17 & 6 \\
\hline Hepatitis $\mathrm{B}+\mathrm{C} \pm \mathrm{DM}$ & 5 & 1.8 \\
\hline $\mathrm{DM} \pm$ alcohol & 10 & 3.6 \\
\hline No risk factors & 15 & 5.4 \\
\hline \multicolumn{3}{|l|}{ BCLC†stage } \\
\hline BCLC stage A & 95 & 34.2 \\
\hline BCLC stage $B$ & 144 & 51.8 \\
\hline BCLC stage C & 27 & 9.7 \\
\hline BCLC stage D & 12 & 4.3 \\
\hline \multicolumn{3}{|l|}{ No of HCC nodules } \\
\hline Unifocal & 140 & 50.4 \\
\hline Multifocal & 138 & 49.6 \\
\hline \multicolumn{3}{|l|}{ Diameter of largest HCC nodule } \\
\hline$\leq 3 \mathrm{~cm}$ & 45 & 16.2 \\
\hline$>3-5 \mathrm{~cm}$ & 119 & 42.8 \\
\hline$>5 \mathrm{~cm}$ & 114 & 41 \\
\hline \multicolumn{3}{|l|}{ AFP } \\
\hline$<300 \mathrm{IU} / \mathrm{ml}$ & 178 & 64 \\
\hline$\geq 300 \mathrm{IU} / \mathrm{ml}$ & 94 & 33.8 \\
\hline Missing & 6 & 2.2 \\
\hline \multicolumn{3}{|l|}{ Treatment } \\
\hline TACE $\ddagger$ & 181 & 65.1 \\
\hline $\begin{array}{l}\text { TACE with other treatments } \\
\text { (Resection, RFA, PEI, Sorafenib) }\end{array}$ & 23 & 8.3 \\
\hline Ablation (RFA, PEI) & 12 & 4.3 \\
\hline Surgical resection & 6 & 2.2 \\
\hline Sorafenib & 14 & 5 \\
\hline Supportive care only & 42 & 15.1 \\
\hline
\end{tabular}


Table 2: Survival of patients with hepatocellular carcinoma according to different parameters

\begin{tabular}{|c|c|c|c|}
\hline Parameter & $\begin{array}{l}\text { Median Survival } \\
\text { (months) }\end{array}$ & $\begin{array}{l}\text { Parameters with } \\
\text { survival comparison }\end{array}$ & $\begin{array}{l}\text { Chi-sq. (df); } P \\
\text { value }\end{array}$ \\
\hline & \multicolumn{3}{|l|}{ Treatment Type } \\
\hline TACE & 24.6 & $\begin{array}{l}\text { TACE \& other } \\
\text { treatment }\end{array}$ & 9.05 (1) 0.003 \\
\hline Surgical resection & 31.5 & $\begin{array}{l}\text { TACE \& surgical } \\
\text { resection }\end{array}$ & 1.89 (1) 0.168 \\
\hline Ablation (PEI, RFA) & 60.7 & TACE \& ablation & 3.90 (1) 0.048 \\
\hline $\begin{array}{l}\text { TACE with other treatment } \\
\text { (Resection RFA,PEI, Sorafenib) }\end{array}$ & 44 & TACE \& Sorafenib & $1.22(1) 0.26$ \\
\hline Sorafenib & 9.6 & TACE \& Supportive care & $\begin{array}{l}123.7(1) \\
<0.001\end{array}$ \\
\hline Supportive care & $\begin{array}{l}3.5 \\
\text { Focality }\end{array}$ & & \\
\hline Unifocal & 26.7 & $\begin{array}{l}\text { Between unifocal \& } \\
\text { multifocal }\end{array}$ & 6.89 (1) 0.009 \\
\hline \multirow[t]{2}{*}{ Multifocal } & 17.4 & & \\
\hline & Tumour Size & & \\
\hline Up to $3 \mathrm{~cm}$ & 33.1 & Up to $3 \&>5$ & 10.03 (1) 0.002 \\
\hline From $3-5 \mathrm{~cm}$ & 23.9 & $>3-5 \&>5$ & 5.86 (1) 0.015 \\
\hline$>5 \mathrm{~cm}$ & $\begin{array}{l}16.1 \\
\text { Child's } \\
\text { classification }\end{array}$ & & \\
\hline \multirow[t]{2}{*}{ A } & 25.4 & Child's A \& B & $\begin{array}{l}12.79(1) \\
<0.001\end{array}$ \\
\hline & 8.8 & Child's A \& C & $\begin{array}{l}198.3(1) \\
<0.001\end{array}$ \\
\hline $\mathrm{C}$ & $\begin{array}{l}1.6 \\
\text { BCLC stage }\end{array}$ & Child's B \& C & $18.1(1)<0.001$ \\
\hline \multirow[t]{2}{*}{ A } & 30.5 & BCLC A \& B & 7.14 (1) 0.008 \\
\hline & 21.1 & BCLC A \& C & $\begin{array}{l}41.28(1) \\
<0.001\end{array}$ \\
\hline $\mathrm{C}$ & 3.77 & BCLC A \& D & $99.7(1)<0.001$ \\
\hline \multirow[t]{4}{*}{$\mathrm{D}$} & 1.67 & BCLC B \& C & $26.4(1)<0.001$ \\
\hline & & BCLC B \& D & $92.6(1)<0.001$ \\
\hline & & BCLC C \& D & 6.9 (1) 0.008 \\
\hline & $A F P$ & & \\
\hline$\leq 299$ & 24.8 & $\leq 299 \& \geq 300$ & 3.05 (1) 0.081 \\
\hline$\geq 300$ & 14.9 & & \\
\hline Overall survival & 23.9 & & \\
\hline
\end{tabular}




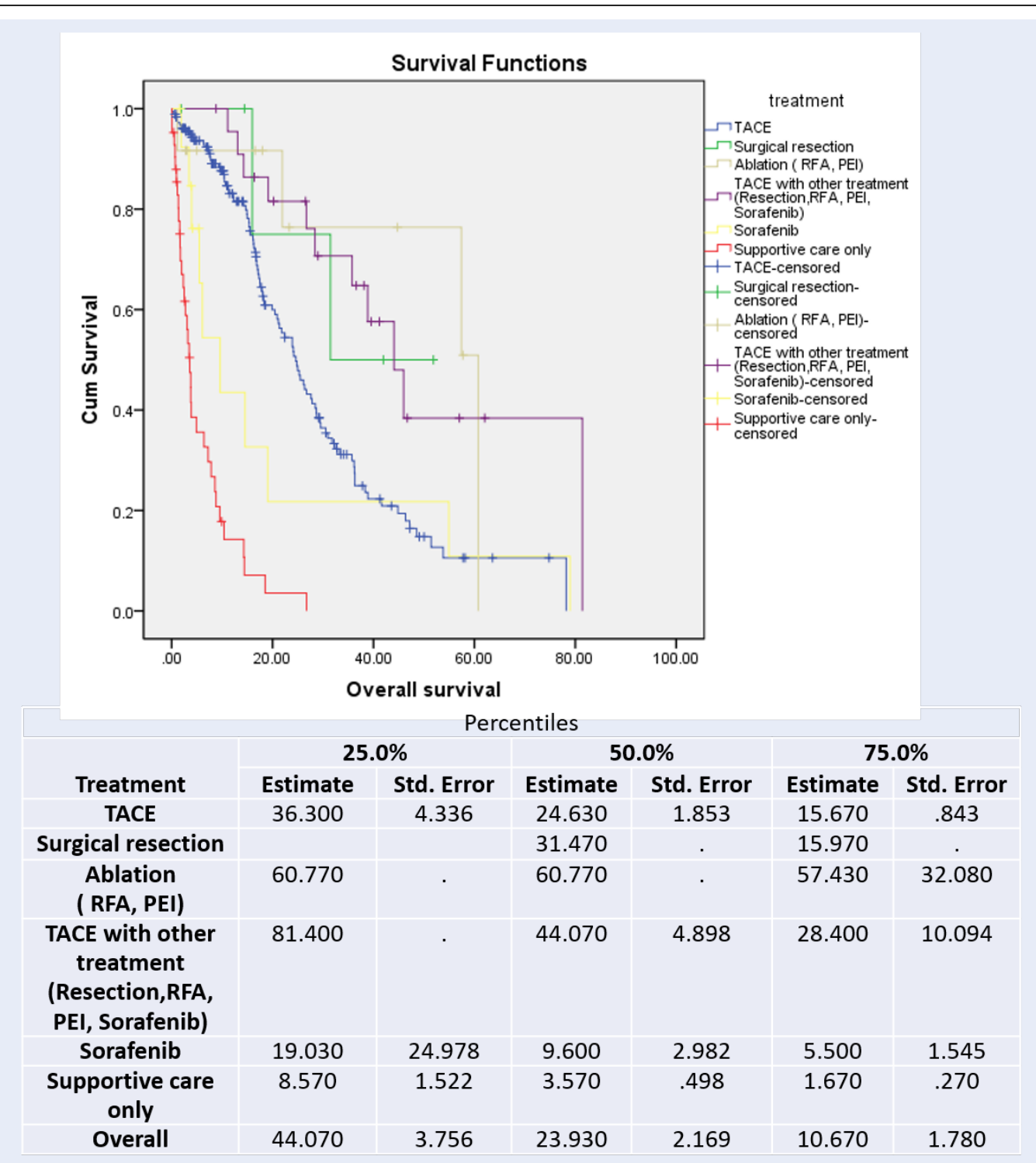

Figure 1: Kaplan-Meir survival curve of different treatment regimens.

difference in survival between patients with tumor size up to $3 \mathrm{~cm}$ and those with size $>5 \mathrm{~cm}$ (Chisq. $=10.03, \mathrm{df}=1, \mathrm{p}=0.002)$, as well as when comparing those with tumor size $3-5 \mathrm{~cm}$ and $>5 \mathrm{~cm}$ (Chi$\mathrm{sq} .=5.86, \mathrm{df}=1, \mathrm{p}=0.015$ ) (Figure 2). There were significant differences in survival according to the ChildPugh status, between Child-Pugh class A \& B (Chisq. $=12.79, \mathrm{df}=1, \mathrm{p}<0.001)$, A \& C (Chi-sq.=198.3, $\mathrm{df}=1, \mathrm{p}<0.001)$, and $\mathrm{B} \& \mathrm{C}$ (Chi-sq. $=18.18, \mathrm{df}=1$, $\mathrm{p}<0.001)$. Similarly, differences between BCLC stage $A \& B, A \& C$, and A \& D, as well as between B \& C, $B \& D$, and C \& D were all statistically significant (pvalues between $<0.001$ and 0.008 ) (Figure 3). Table 2 shows the Chi-square values and $\mathrm{p}$-values for the dif- ferences mentioned above.

Several other parameters were also subjected to univariate analysis but were not found to be significant. These included AFP values, for which we used values $\leq 299$ and $\geq 300$ as cut-off values $(p=0.081)$. Similarly, the difference in survival by risk factor was also not significant $(\mathrm{p}=0.14)$. However, there was a significant association between categories of AFP level $(<200$ and $>/=200$ ) and tumor size (up to $3 \mathrm{~cm},>3 \mathrm{~cm}$, $3-5 \mathrm{~cm}$, and $>5 \mathrm{~cm}$.); Chi-sq. $=9.45, \mathrm{df}=2, \mathrm{p}=0.009$.

\section{DISCUSSION}

About $4.8 \%$ of the Pakistani population is estimated to be infected with hepatitis $C$, mainly genotype $3 a$, and 


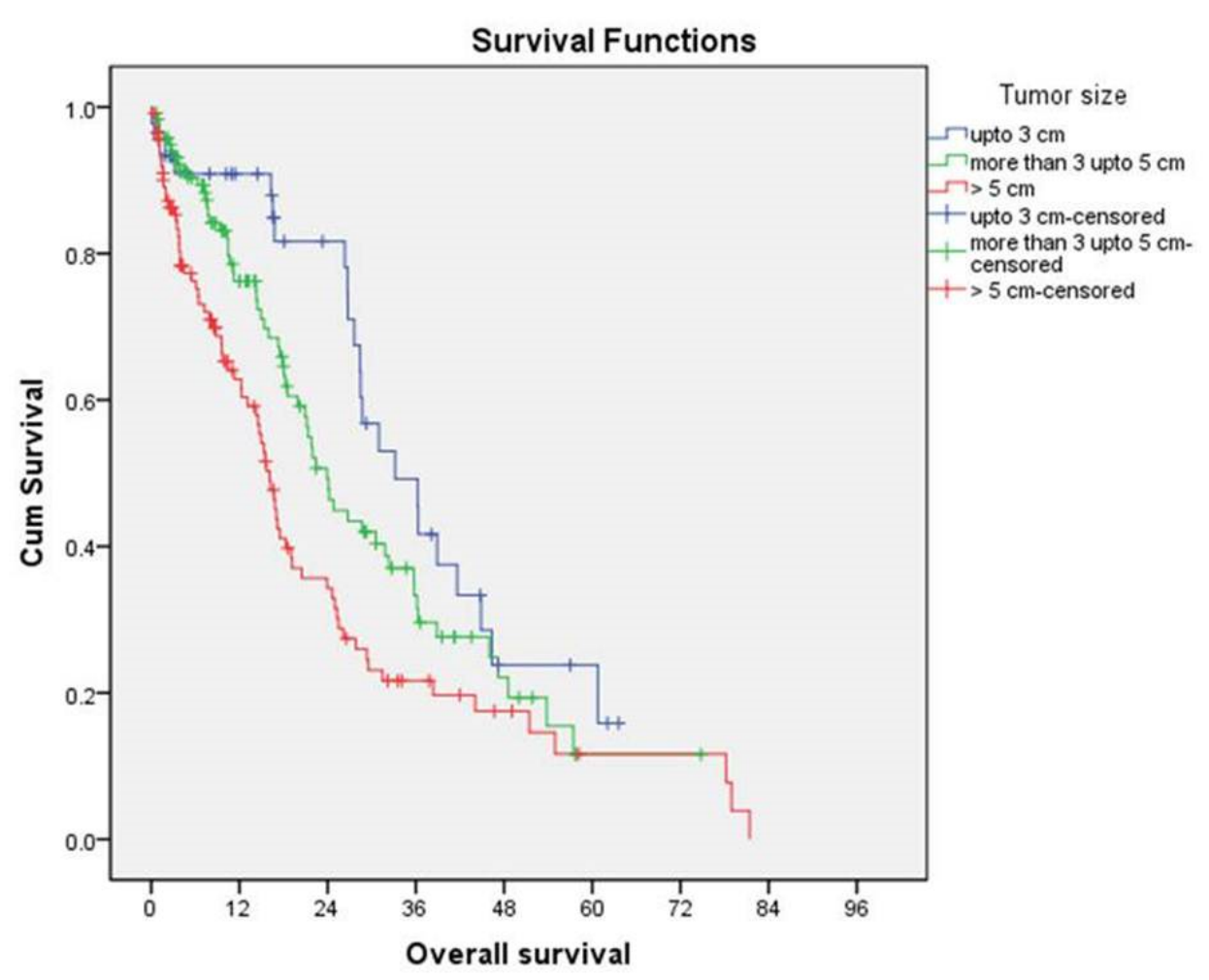

\begin{tabular}{|c|c|c|c|c|}
\hline & \multicolumn{3}{|c|}{ Case Processing Summary } & \\
\hline & & & \multicolumn{2}{c|}{ Censored } \\
\hline Tumor size & Total N & No of Events & N & Percent \\
\hline Up to $\mathbf{3 ~ c m}$ & 45 & 23 & 22 & $48.9 \%$ \\
\hline $\mathbf{3 - 5}$ cm & 119 & 62 & 57 & $47.9 \%$ \\
\hline$>5$ cm & 114 & 75 & 39 & $34.2 \%$ \\
\hline Overall & 278 & 160 & 118 & $42.4 \%$ \\
\hline
\end{tabular}

Figure 2: Kaplan-Meir survival curve according to different tumour sizes.

another $2.5 \%$ are estimated to have chronic hepatitis B infection ${ }^{10,11}$. The incidence of HCC in Pakistan in males is about 7.5 per 100,000 , while for females this estimate is 2.8 per 100,000 persons per year ${ }^{12,13}$. About $60-70 \%$ of these patients with HCC are infected with hepatitis C, another $20 \%$ are infected with hepatitis B, while other causes account for only $10-15 \%$ of cases ${ }^{14,15}$

In our study, 236 patients $(84.8 \%)$ had a prior infection with hepatitis C. Although 234 patients (84\%) were in Child-Pugh class A at the time of diagnosis, nearly half of the patients (138 or $49.6 \%$ ) had multifocal tumors at presentation. The majority of our patients had advanced disease with poor clinical status and liver function, as evidenced by intermediate
BCLC stage B in 144 patients (51.8\%), and were candidates for TACE only. Indeed, 95 (34.2\%) presented with BCLC stage A, while 39 (14\%) had BCLC C and $\mathrm{D}$, and only 95 (34.2\%) were diagnosed as BCLC stage A. Of the 95 patients in BCLC stage A, only 6 patients $(2.2 \%)$ were judged suitable for surgical resection since many patients with apparently resectable lesions had evidence of portal hypertension, as shown by the presence of varices, platelet count of $<100,000$, or hepatic venous pressure gradient of $>12 \mathrm{~mm} \mathrm{Hg}$. Only $12(4.3 \%)$ patients underwent ablative procedures because of tumor location, size or other technical issues, resulting in a huge number of patients undergoing TACE.

Median survival with various treatments was 23.9 months, while it was 24.6 months with TACE. Abla- 


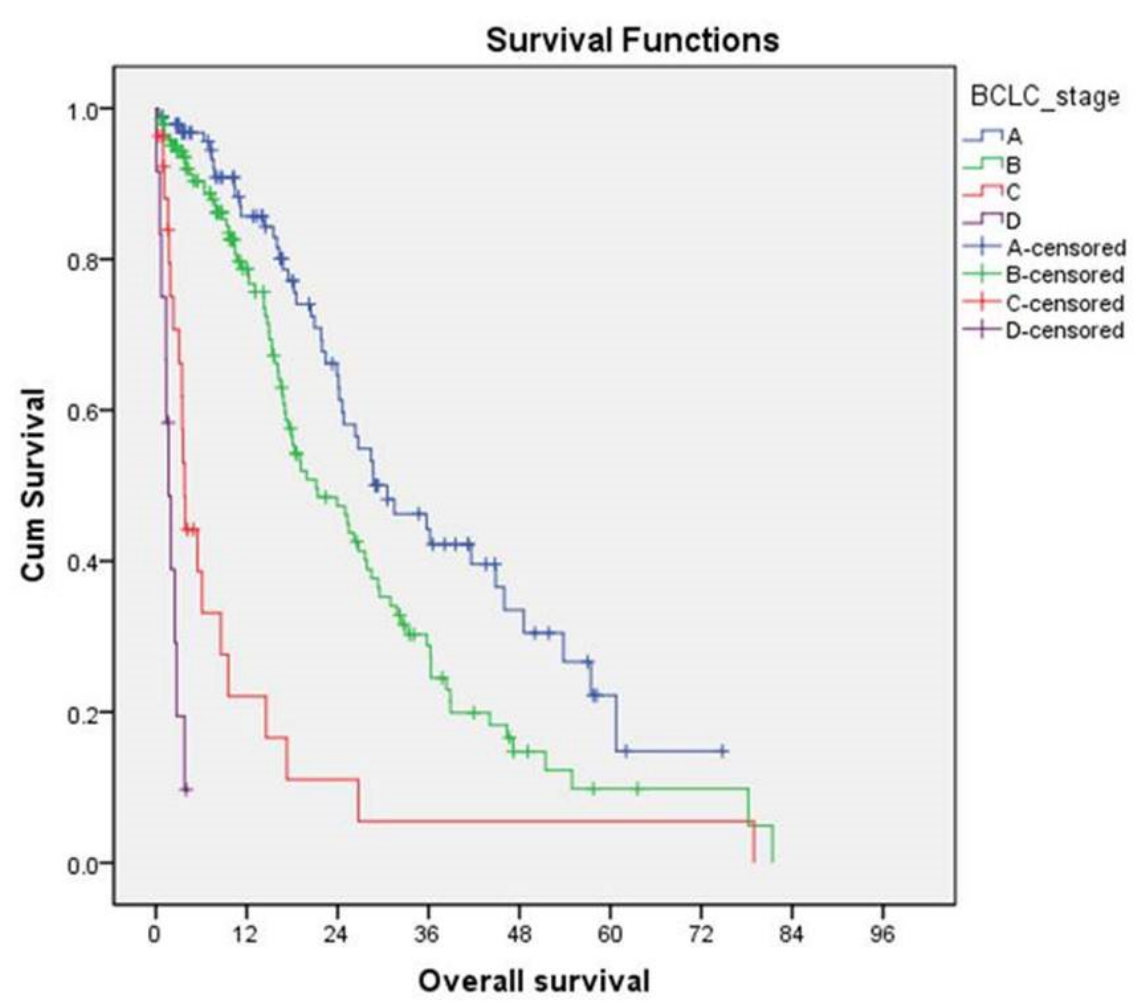

\begin{tabular}{|c|c|c|c|c|}
\hline \multicolumn{5}{|c|}{ Case Processing Summary } \\
\hline BCLC stage & Total N & No of Events & \multicolumn{2}{|c|}{ Censored } \\
\hline A & 95 & 46 & 49 & $51.6 \%$ \\
\hline B & 144 & 83 & 61 & $42.4 \%$ \\
\hline C & 27 & 21 & 6 & $22.2 \%$ \\
\hline D & 12 & 10 & 2 & $16.7 \%$ \\
\hline Overall & 278 & 160 & 118 & $42.4 \%$ \\
\hline
\end{tabular}

Figure 3: Kaplan-Meir survival curve according to BCLC stage.

tive procedures and surgery were associated with better survival of 61 months versus 31.5 months. This improved survival did not reach statistical significance, possibly because of the small numbers of patients in these two groups. Patients with small tumor size, up to $3 \mathrm{~cm}$, had better survival ( $\mathrm{p}=0.002$ ), which is in keeping with prior studies. In the study by Grieco et al., in which $95.9 \%$ of patients had liver cirrhosis, the mean duration of survival of the total study population was 25.7 months. Moreover, the authors noted that the absence of portal vein thrombosis, small tumor size, and low bilirubin levels were significantly correlated with survival; $p=0.006,0.016$ and
0.012 , respectively ${ }^{16}$. Similarly, other studies have also shown a worse prognosis in those with multiple tumors and increasing tumor size, irrespective of vascular invasion ${ }^{17,18}$. In the study by Ueno et al., which had a higher percentage of patients without cirrhosis (19.2\%), the mean survival was also higher, at 37.7 months ${ }^{19}$. Studies have also shown that there is a correlation between serum AFP levels and microvascular invasion, as well as tumor size 20,21 .

There is high mortality in patients who develop HCC in the context of co-existent hepatitis B and HIV. The incidence and mortality of HCC have been increasing slowly in areas of low incidence and decreasing in ar- 
eas of high incidence. However, the WHO data shows a progressive increase in the number of patients diagnosed with primary liver cancer from 437,408 in 1990 to 716,600 in $2002^{22}$.

In a study of 645 patients with HCC in Pakistan, $82.9 \%$ of patients were diagnosed to have HCC only when they became symptomatic, while only $8.2 \%$ were diagnosed on screening. This explains why the majority of our patients present with advanced, often multifocal disease. The absence of a national screening program means that this situation is unlikely to change soon. Even for those fortunate enough to be diagnosed early, the absence of a national liver transplant program significantly limits treatment options ${ }^{15}$. Most patients in our series presented with advanced liver disease with multifocal tumors and were candidates for palliative treatment only.

\section{CONCLUSIONS}

There is an urgent need for public education to minimize hepatitis B and C transmission, a nationwide screening program to detect disease at an earlier stage, and the development of specialist liver units and liver transplant programs. These are especially needed in high endemic areas of the world with hepatitis B and C, which are mostly developing countries with low educational status and significant recourse constraints.

\section{ABBREVIATIONS}

AASLD: American Association for the Study of Liver Diseases

AFP: Alpha fetoprotein

BCLC: Barcelona clinic liver cancer

CT: Computerized tomography

DM: Diabetes mellitus

DNA: Deoxyribonucleic acid

EASL: European Association for the Study of the Liver

HBV: Hepatitis B virus

HCC: Hepatocellular carcinoma

HCV: Hepatitis C virus

MRI: Magnetic resonance imaging

PCR: Polymerase chain reaction

PEI: Percutaneous ethanol injection

RFA: Radiofrequency ablation

RNA: Ribonucleic acid

SD: Standard deviation

TACE: Transarterial chemoembolization

WHO: World health organization

\section{COMPETING INTERESTS}

The authors declare that they have no competing interest.

\section{AUTHORS' CONTRIBUTIONS}

All authors contributed significantly in this research paper. Hala Mansoor, Muhammad Adnan Masood and Kashif Siddique were involved in acquisition, analysis and interpretation of data, as well in drafting the article and rewriting after critical analysis. Farhana Badar and Muhammed Aasim Yusuf were involved in data analysis and in critical review of the paper including the final proof version.

\section{REFERENCES}

1. Yang JD, Roberts LR. Hepatocellular carcinoma: A global view. Nat Rev Gastroenterol Hepatol. 2010;7(8):448-58. PMID: 20628345. Available from: 10.1038/nrgastro.2010.100.

2. Kinoshita A, Onoda H, Imai N, I waku A, Oishi M, Tanaka K, et al. The Glasgow Prognostic Score, an inflammation based prognostic score, predicts survival in patients with hepatocellular carcinoma. BMC Cancer. 2013;13(1):52. PMID: 23374755. Available from: 10.1186/1471-2407-13-52.

3. Parkin DM, Bray F, Ferlay J, Pisani P. Global cancer statistics, 2002. CA Cancer J Clin. 2005;55(2):74-108. PMID: 15761078. Available from: 10.3322/canjclin.55.2.74.

4. El-Serag HB. Hepatocellular carcinoma: recent trends in the United States. Gastroenterology. 2004;127(5):27-34. PMID: 15508094. Available from: 10.1053/j.gastro.2004.09.013.

5. Morgan TR, Mandayam S, Jamal MM. Alcohol and hepatocellular carcinoma. Gastroenterology. 2004;127(5):87-96. PMID: 15508108. Available from: 10.1053/j.gastro.2004.09.020.

6. Gomaa Al, Khan SA, Toledano MB, Waked I, Taylor-Robinson SD. Hepatocellular carcinoma: epidemiology, risk factors and pathogenesis. World J Gastroenterol. 2008;14(27):43008. PMID: 18666317. Available from: 10.3748/wjg.14.4300.

7. Singal AG, Pillai A, Tiro J. Early detection, curative treatment, and survival rates for hepatocellular carcinoma surveillance in patients with cirrhosis: a meta-analysis. PLoS Med. 2014;11(4):e1001624. PMID: 24691105. Available from: 10. 1371/journal.pmed.1001624.

8. Cabibbo G, Enea M, Attanasio M, Bruix J, CraxìA, Cammà C. A meta-analysis of survival rates of untreated patients in randomized clinical trials of hepatocellular carcinoma. Hepatology. 2010;51(4):1274-83. PMID: 20112254. Available from: 10.1002/hep.23485.

9. Yusuf MA, Badar F, Meerza F, Khokhar RA, Ali FA, Sarwar S, et al. Survival from hepatocellular carcinoma at a cancer hospital in Pakistan. Asian Pac J Cancer Prev. 2007;8(2):272-4. PMID: 17696722.

10. Abbas Z, Jafri W, Hamid S, for the Study of Liver Diseases PS. Management of hepatitis B: Pakistan Society for the Study of Liver Diseases (PSSLD) practice guidelines. J Coll Physicians Surg Pak. 2010;20(3):198-201. PMID: 20392385.

11. Qureshi H, Bile KM, Jooma R, Alam SE, Afridi HU. Prevalence of hepatitis $B$ and $C$ viral infections in Pakistan: findings of a national survey appealing for effective prevention and control measures. East Mediterr Health J. 2010;16:15-23. PMID: 21495584. Available from: 10.26719/2010.16.Supp.15.

12. Bhurgri $Y$, Bhurgri A, Pervez S, Bhurgri M, Kayani N, Ahmed R, et al. Cancer profile of Hyderabad, Pakistan 1998-2002. Asian Pac J Cancer Prev. 2005;6(4):474-80. PMID: 16435995.

13. Bhurgri Y, Pervez S, Kayani N, Bhurgri A, Usman A, Bashir I, et al. Cancer profile of Larkana, Pakistan (2000-2002). Asian Pac J Cancer Prev. 2006;7(4):518-21. PMID: 17250420.

14. Butt AS, Hamid S, Wadalawala AA, Ghufran M, Javed AA, Farooq $\mathrm{O}$, et al. Hepatocellular carcinoma in Native South Asian Pakistani population; trends, clinico-pathological characteristics \&amp; differences in viral marker negative \&amp; viralhepatocellular carcinoma. BMC Res Notes. 2013;6(1):137. PMID: 23566475. Available from: 10.1186/1756-0500-6-137. 
15. Butt AS, Abbas Z, Jafri W. Hepatocellular carcinoma in pakistan: where do we stand? Hepat Mon. 2012;12:e6023. PMID: 23166534.

16. Grieco A, Pompili M, Caminiti G, Miele L, Covino M, Alfei B, et al. Prognostic factors for survival in patients with earlyintermediate hepatocellular carcinoma undergoing nonsurgical therapy: comparison of Okuda, CLIP, and BCLC staging systems in a single Italian centre. Gut. 2005;54(3):411-8. PMID: 15710992. Available from: 10.1136/gut.2004.048124.

17. Minagawa $M$, Ikai I, Matsuyama $Y$, Yamaoka $Y$, Makuuchi M. Staging of hepatocellular carcinoma: assessment of the Japanese TNM and AJCC/UICC TNM systems in a cohort of 13,772 patients in Japan. Ann Surg. 2007;245(6):909-22. PMID: 17522517. Available from: 10.1097/01.sla.0000254368. 65878.da.

18. Nathan H, Schulick RD, Choti MA, Pawlik TM. Predictors of survival after resection of early hepatocellular carcinoma. Ann Surg. 2009;249(5):799-805. PMID: 19387322. Available from:
10.1097/SLA.0b013e3181a38eb5.

19. Ueno S, Tanabe G, Sako K, Hiwaki T, Hokotate H, Fukukura $\mathrm{Y}$, et al. Discrimination value of the Western prognostic system (CLIP score) for hepatocellular carcinoma in 662 Japanese patients. Hepatology. 2001;34(3):529-34. PMID: 11526539. Available from: 10.1053/jhep.2001.27219.

20. Abbasi A, Bhutto AR, Butt N, Munir SM. Corelation of serum alpha fetoprotein and tumor size in hepatocellular carcinoma. J Pak Med Assoc. 2012;62(1):33-6. PMID: 22352098.

21. McHugh PP, Gilbert J, Vera S, Koch A, Ranjan D, Gedaly R Alpha-fetoprotein and tumour size are associated with microvascular invasion in explanted livers of patients undergoing transplantation with hepatocellular carcinoma. HPB (Oxford). 2010;12(1):56-61. PMID: 20495646. Available from: 10.1111/j.1477-2574.2009.00128.x.

22. El-Serag HB. Epidemiology of viral hepatitis and hepatocellular carcinoma. Gastroenterology. 2012;142(6). PMID: 22537432. Available from: 10.1053/j.gastro.2011.12.061. 